\title{
Presencia de larvas de Aedes aegypti en tres sectores de la provincia de Chepén, Perú
}

\author{
Presence of Aedes aegypti larvae in three sectors of the \\ province of Chepén, Peru
}

\author{
Johnny Leandro Saavedra-Camacho 1,a, Sebastián Iglesias-Osores 1,a
}

\section{Sr. Editor:}

El dengue es una enfermedad viral de gran prevalencia a nivel mundial que ha incrementado desmesuradamente en los últimos años en zonas tropicales. El agente etiológico, el virus dengue, es transmitido por mosquitos del género Aedes, principalmente por la especie Aedes aegypti (1). Por tanto, la presencia y los brotes de estas arbovirosis se relacionan a la presencia del vector. Este mosquito es originario del continente africano, siendo no solo vector del dengue sino también del virus de la fiebre amarilla, virus del zika y el virus de la chikungunya; además, este culícido se encuentra adaptado a climas tropicales y subtropicales del mundo, y ha persistido en las regiones caribeñas desde el siglo XVIII, expandiéndose a casi toda América (2). Precisamente, este tipo de climas tropicales es favorable para el crecimiento y desarrollo del mosquito en mención. El ciclo vital del mosquito se divide en cuatro etapas: huevo, larva, pupa y adulto. Las larvas son exclusivamente de ambiente acuático; se distinguen a simple vista de otros géneros debido a que en la superficie del agua se mantienen casi verticales, son blanquecinas y su sifón respiratorio es corto y grueso. En condiciones óptimas, el periodo de desarrollo larval es de 1 a 2 semanas. La mayor parte de los recipientes para almacén de agua (barriles, tinas, baldes, etc.) y recipientes para inservibles (cilindros, llantas, botellas) sirven como criaderos ${ }^{(3)}$.

En los últimos años se han realizado escasos estudios de depósitos como sitios de reproducción de la larva de $A$. aegypti en distintos países de Latinoamérica. Al respecto, una investigación en República Dominicana se reportó la presencia de la larva en casi el $18 \%$ de los recipientes analizados, además se encontró que 28 depósitos distintos fueron colonizados por larvas de este mosquito; y la tercera parte de ellos eran utilizados para acumular agua de consumo familiar (4). Por otro lado, en Bolivia se evidenció que poco más de la mitad de las casas inspeccionadas fueron positivas y que hubo mayor predominancia de larvas del mosquito en estudio en llantas, barriles y depósitos desechables ${ }^{(5)}$. En Perú, si bien, las actividades de vigilancia epidemiológica regionales comprenden la valoración de índice aédico, son muy pocas las publicaciones acerca de este tema. Una de ellas menciona que diferentes distritos de la ciudad de Huánuco, las larvas de $A$. aegypti fueron más frecuentes en barriles y floreros seguidos de llantas y baldes ${ }^{(6)}$.

Por tal motivo, en la provincia de Chepén se estudió la presencia de larvas de A. aegypti en distintos depósitos que almacenaban agua de tres sectores de esa ciudad (Chepén, Pacanguilla y Pacanga) durante los meses de octubre a diciembre del año 2020, inspeccionando los depósitos que almacenaban agua u otros inservibles, no teniendo en cuenta la cantidad de larvas del mosquito encontradas por depósito, solo se consideró la presencia tomando como referencia las características típicas de dicha larva descritas en la Guía Práctica para la Identificación de A. aegypti del Ministerio de Salud (7). Encontrando a los cántaros de barro del sector Chepén con el mayor porcentaje de larvas con respecto a los depósitos inspeccionados, seguido de los floreros del sector Pacanguilla (Tabla 1).

\footnotetext{
${ }^{1}$ Facultad de Ciencias Biológicas, Universidad Nacional Pedro Ruiz Gallo, Lambayeque, Perú.

a Biólogo
} 
Tabla 1. Presencia de larvas de Aedes aegypti en depósitos inspeccionados en tres sectores de la provincia de Chepén, Perú, durante octubre a diciembre del 2020.

\begin{tabular}{|c|c|c|c|c|}
\hline Lugar & Condición & Chepén & Pacanguilla & Pacanga \\
\hline \multirow{2}{*}{ Casas } & Inspeccionado & 16950 & 2714 & 448 \\
\hline & Positivo N (\%) & $48(0,28)$ & $3(0,11)$ & $0(0,00)$ \\
\hline \multirow{2}{*}{ Depósitos } & Inspeccionado & 44755 & 7850 & 1554 \\
\hline & Positivo N (\%) & $64(0,14)$ & $3(0,04)$ & $0(0,00)$ \\
\hline \multirow{2}{*}{ Tanque elevado } & Inspeccionado & 7684 & 1059 & 245 \\
\hline & Positivo N (\%) & $0(0,00)$ & $0(0,00)$ & $0(0,00)$ \\
\hline \multirow{2}{*}{ Tanque bajo } & Inspeccionado & 517 & 99 & 24 \\
\hline & Positivo N (\%) & $0(0,00)$ & $0(0,00)$ & $0(0,00)$ \\
\hline \multirow{2}{*}{ Barriles, Toneles, Cilindros } & Inspeccionado & 8914 & 1542 & 328 \\
\hline & Positivo N (\%) & $24(0,27)$ & $2(0,13)$ & $0(0,00)$ \\
\hline \multirow{2}{*}{ Cántaro de barro } & Inspeccionado & 79 & 1 & 0 \\
\hline & Positivo N (\%) & $5(6,33)$ & $0(0,00)$ & $0(0,00)$ \\
\hline \multirow{2}{*}{ Llantas } & Inspeccionado & 11 & 5 & 1 \\
\hline & Positivo N (\%) & $0(0,00)$ & $0(0,00)$ & $0(0,00)$ \\
\hline \multirow{2}{*}{ Floreros } & Inspeccionado & 598 & 65 & 34 \\
\hline & Positivo N (\%) & $4(0,67)$ & $1(1,54)$ & $0(0,00)$ \\
\hline \multirow{2}{*}{ Tinas, Baldes, Bateas } & Inspeccionado & 16309 & 3377 & 649 \\
\hline & Positivo N (\%) & $20(0,12)$ & $0(0,00)$ & $0(0,00)$ \\
\hline \multirow{2}{*}{ Ollas } & Inspeccionado & 93 & 15 & 5 \\
\hline & Positivo N (\%) & $0(0,00)$ & $0(0,00)$ & $0(0,00)$ \\
\hline \multirow{2}{*}{ Inservibles } & Inspeccionado & 10549 & 1686 & 268 \\
\hline & Positivo N (\%) & $11(0,10)$ & $0(0,00)$ & $0(0,00)$ \\
\hline
\end{tabular}

Es bien conocido que los depósitos e inservibles pueden albergar larvas de mosquitos que transmiten el dengue, estos en ambientes tropicales donde llueve y existen temperaturas templadas es un sitio para su proliferación. El control epidemiológico de éstos debe ser una tarea primordial en zonas templadas con estas características. El seguimiento mediante trampas para mosquitos y concientización de la población podrían ser las soluciones. Se debe, además, educar a la población para no conservar envases descartados y de tapar los que si usen, no permitiendo la entrada de mosquitos para que depositen sus huevos. Esto sobre todo es un problema cultural de las poblaciones en riesgo en lo cual se debe trabajar para concientizar a las personas.

La presencia de larvas de $A$. aegypti en el presente estudio fue demasiado inferior en relación a una investigación hecha en Cuba, donde obtuvieron $41 \%$ de positividad en casas y $18 \%$ en recipientes, siendo los tanques plásticos los criaderos más frecuentes, esto se explica en el clima tropical y muy lluvioso de la ciudad cubana que se estudió (4); lo mismo ocurre con lo investigado en una ciudad boliviana donde se detectó un $52 \%$ de larvas del mosquito en las casas inspeccionadas y cerca de un $22 \%$ en los recipientes analizados, teniendo en cuenta la capacidad de
A. aegypti para adaptarse a un lugar con gran altitud y un clima ligeramente templado ${ }^{(5)}$. Por otro lado, un estudio realizado en Huánuco obtuvo resultados similares a la presente investigación, debido a que se encontraron $2,6 \%$ de casas positivas y menos del $3 \%$ en recipientes, encontrando a los barriles como foco más frecuente seguido de los floreros ${ }^{(6)}$, lo que indica que en climas templados como en Chepén y Huánuco, el mosquito puede desarrollarse con normalidad, inclusive si la altitud es mayor.

La presencia de larvas de $A$. aegypti en las casas y recipientes de tres sectores de la provincia de Chepén, Perú no superó el 0,5\%. El depósito con mayor positividad fue el cántaro de barro del sector Chepén con $6,33 \%$ seguido de los floreros del sector Pacanguilla con $1,54 \%$ y los floreros del sector Chepén con $0,67 \%$.

Conflictos de interés: Los autores declaran que no tienen conflicto de intereses.

Fuentes de financiamiento: Autofinanciado 


\section{REFERENCIAS BIBLIOGRÁFICAS}

1. Perez M. Evaluación del temefos y pyriproxifeno para el control de larvas de Aedes aegypti en condiciones de laboratorio. Horiz Med [Internet]. 2017;17(4):24-9. Disponible en: http://www.scielo.org.pe/pdf/hm/v17n4/ a05v17n4.pdf

2. Guzmán MG, García G, Kourí G. Dengue y fiebre hemorrágica del dengue, un problema de salud mundial. Rev Cubana Med Trop [Internet]. 2008;60(1):5-16. Dsiponible en: http://scielo.sld.cu/pdf/mtr/v60n1/ mtr01108.pdf

3. Chico P, Hidalgo F, Ochoa R. Ciclo de vida del Aedes aegypti y manifestaciones clínicas del dengue. Acta Pedíatrica México. 2001;22(2):114-7.

4. Diéguez L, Borge M, Rodríguez MA, Vásquez YE, Alarcón PM. Un acercamiento al conocimiento de los hábitats larvarios de Aedes (Stegomyia) aegypti (Diptera: Culicidae) en el entorno doméstico en Jarabacoa, República Dominicana. Rev Cubana Med Trop [Internet]. 2019;71(3). Disponible en: http://scielo.sld.cu/pdf/mtr/v71n3/1561-3054-mtr-71-03-e386.pdf

5. Aquino EE, Gamboa Ortuño LP, Gueresa JA, Agreda Herbas M. Fuentes predominantes de la colonización de Aedes aegypti que facilita el proceso de disperción en el municipio de Colcapirhua. Rev Científica Salud UNITEPC [Internet]. 2018;5(2):64-77. Disponible en: https://investigacion.unitepc.edu.bo/revista/index.php/revista-unitepc/article/view/42/66

6. Soto BJ. Características e indicadores entomológicos en la presencia de larvas de (Aedes aegypti) en la vigilancia del control antivectorial del dengue en ocho distritos de la red de salud de Huánuco [Internet]. Universidad Nacional "Hermilio Valdizan"; 2019. Disponible en: http://repositorio.unheval.edu.pe/bitstream/handle/UNHEVAL/5081/TMV00292S71.pdf?sequence $=1$ \&isAllowed $=y$

7. Balta R. Guia practica para la identificacion de A. aegypti [Internet]. $2^{\circ}$. Martínez-Vargas A, Cabezas C, Carrillo C, Chang J, editors. Lima: Ministerio de Salud; 1997. Disponible en: http://bvs.minsa.gob.pe/local/minsa/3013.PDF 